\title{
BECKENBODEN- SCHRITTMACHER
}

ÜBERBLICK TESTUNG \& EINGRIFF

1. TESTUNG: ANLEGEN DER ELEKTRODE

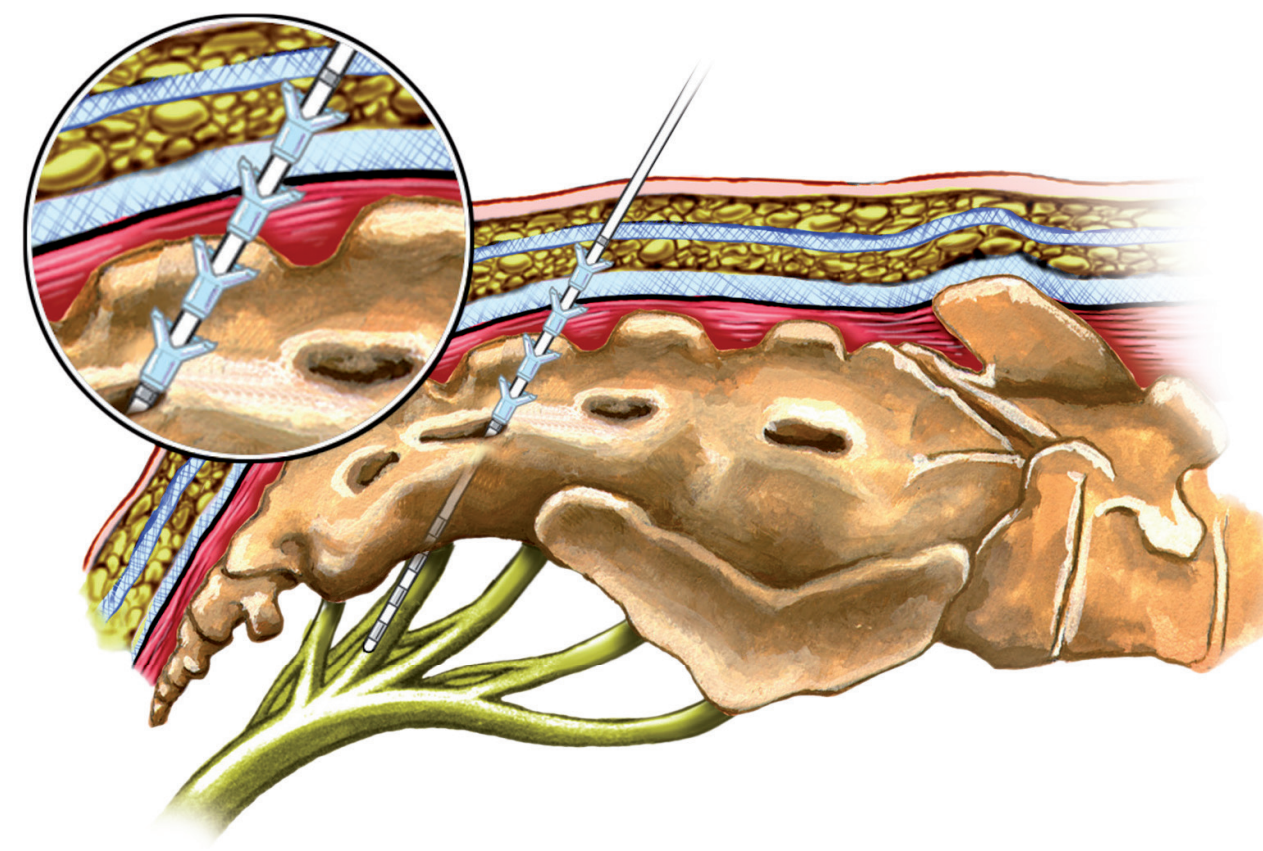

2. TESTPHASE

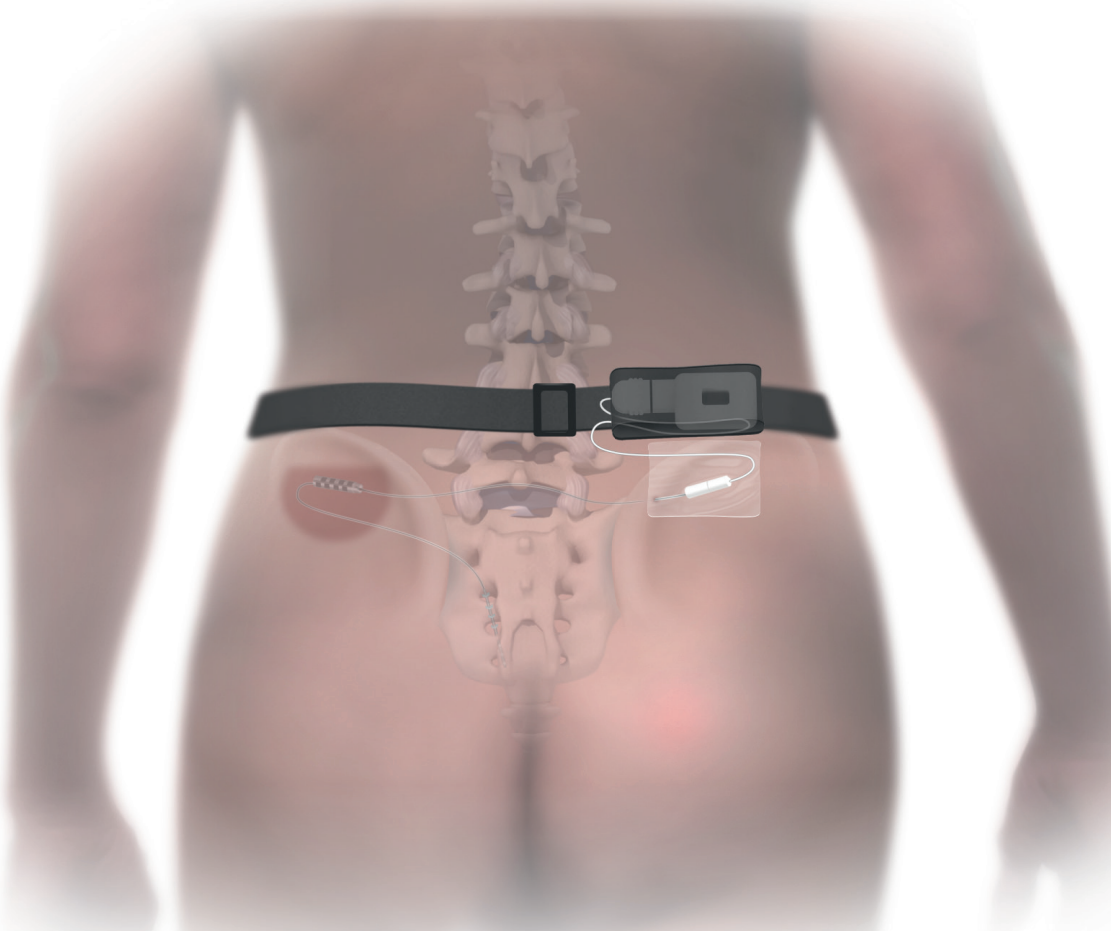

\section{TESTSYSTEM}

\section{Medtronic}

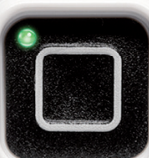

जिए

Meditronic

\section{$\triangle$ \\ $\nabla$}




\section{EINSETZEN DES BECKENBODENSCHRITTMACHERS}

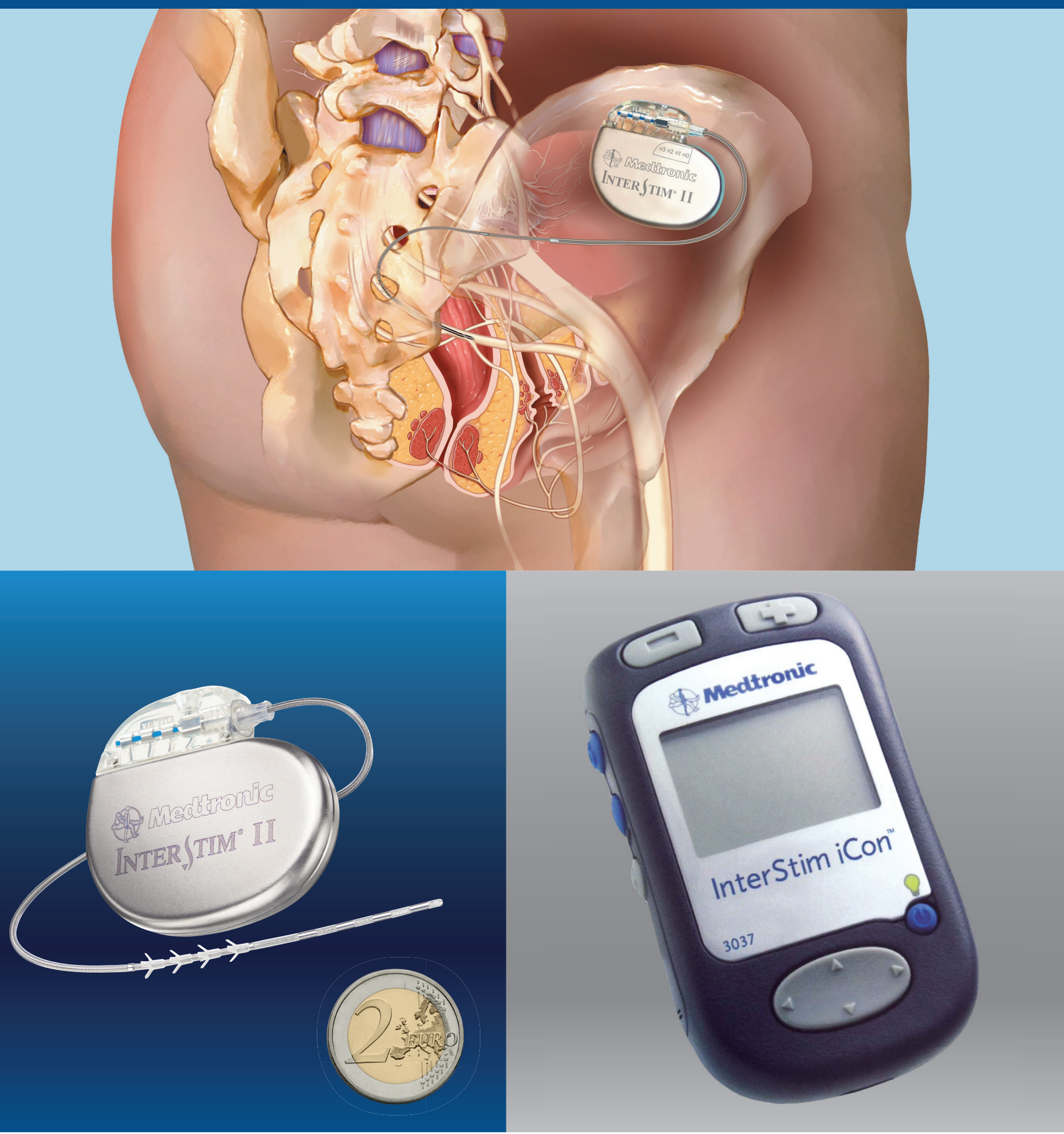

\section{Medtronic}

Deutschland

Medtronic $\mathrm{GmbH}$

Earl-Bakken-Platz 1

DE-40670 Meerbusch

deutschland@medtronic.com

www.medtronic.de

Telefon: +49(0)215981490

Telefax: +49(0)21598149100

\section{Europa}

Medtronic International Trading Sàrl.

Route du Molliau 31

Case postale

$\mathrm{CH}-1131$ Tolochenaz

www.medtronic.eu

Telefon: $+41(0) 218027000$

Telefax: +41(0)21802 7900
Alle Produktabbildungen in Originalgröße Diese Übersicht ersetzt nicht die Benutzerhandbücher der dargestellten Produkte. Die Benutzerhandbücher gehen den Inhalten dieser Übersicht vor. 